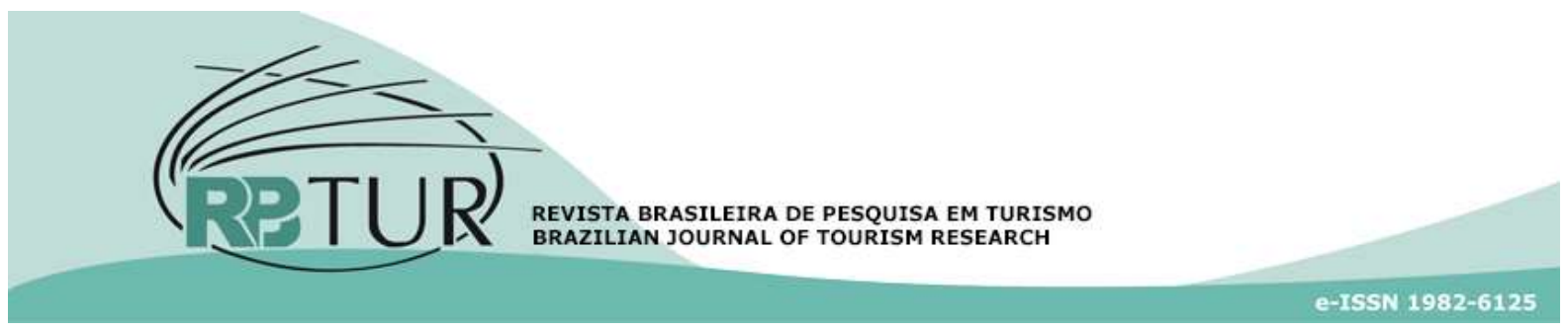

Artículo

DOI: http://dx.doi.org/10.7784/rbtur.v12i3.1508

\title{
¿Turismo juvenil? Los viajes en las biografías de jóvenes de barrios populares de Buenos Aires
}

\author{
Turismo juvenil? As viagens na biografias de jovens de bairros \\ populares de Buenos Aires
}

\section{Youth tourism? Traveling in the biographies of young people of popular neighbourhoods of Buenos Aires}

\begin{abstract}
Silvia Alejandra Tapia ${ }^{1}$
Resumen: En este artículo presento resultados de mi tesis doctoral cuyo objetivo general es analizar las experiencias de jóvenes de barrios populares de Buenos Aires, indagando articulaciones entre movilidades y corporalidades en sus procesos de individuación. Se propuso un abordaje cualitativo, siguiendo los lineamientos de la teoría fundamentada. Se realizaron entrevistas semi-estructuradas, relatos biográficos y observación participante en una organización social que ofrece talleres circenses gratuitos a jóvenes de barrios populares. Investigaciones comienzan a advertir el turismo juvenil, destacando el aumento de jóvenes viajeros y los núcleos turísticos creados en torno a éstos. Ahora bien, las posibilidades de viajar y vacacionar difiere entre distintos grupos sociales, por lo que su abordaje se vuelve una forma de reconocer desigualdades. En este trabajo se identifican las características de los viajes presentes en las biografías de jóvenes entrevistados, el modo en que son percibidos, los sentidos en torno éstos, así como los facilitadores y las limitaciones para llevarlos a cabo. De los emergentes en sus relatos se distinguen tres tipos de viajes: posibilitados y motivados por vínculos familiares, propuestos por agrupaciones religiosas asentadas en barrios populares de la ciudad para supervivencia en la naturaleza y proyectados a futuro, como deseo de movilidad potencial.
\end{abstract}

Palabras clave: Turismo infanto-juvenil. Desigualdades sociales. Turismo y sociología.

Resumo: Neste artigo apresento resultados de minha tese de doutorado cujo objetivo geral é analisar as experiências de jovens dos bairros populares de Buenos Aires, investigando articulações entre mobilidades e corporalidades em seus processos de individuação. A abordagem qualitativa foi proposta, seguindo as diretrizes da teoria fundamentada. Entrevistas semiestruturadas, relatos biográficos e observação participante foram realizados em uma organização social que oferece oficinas gratuitas de circo para jovens de bairros populares. As investigações começam a alertar o turismo jovem, destacando o aumento de jovens viajantes e os centros turísticos criados em torno deles. No entanto, as possibilidades de viajar e sair de férias diferem entre os grupos

\footnotetext{
${ }^{1}$ Universidad de Buenos Aires (UBA), Buenos Aires, Argentina.
}

Artículo recibido en: 12/09/2018. Artículo aprobado en: 18/10/2018. 
sociais, por isso a sua abordagem torna-se uma forma de reconhecer as desigualdades sociais. Este artigo identifica as características das viagens presentes nas biografias dos jovens entrevistados, a maneira como eles as percebem, os sentidos ao seu redor, bem como os facilitadores e as limitações para realizá-los. Dos emergentes em suas histórias destacam-se três tipos de viagens: possíveis e motivadas por laços familiares, propostos por grupos religiosos estabelecidos em bairros populares da cidade para sobrevivência na natureza e projetados para o futuro, como desejo de mobilidade potencial.

Palavras-chave: Turismo infanto-juvenil. Desigualdade social. Turismo e sociologia.

Abstract: In this article, I present results of my doctoral thesis whose general objective is to analyse the experiences of young people from Buenos Aires' popular neighbourhoods, investigating articulations between mobilities and corporalities in their individuation processes. A qualitative approach was proposed, following the directives of the grounded theory. Semi-structured interviews, biographical focus and participant observation were conducted in a social organization that offers free circus workshops to young people from popular neighbourhoods. Research begin to warn about youth tourism, highlighting the increase of young travellers and tourist centres created around them. However, the possibilities of traveling and 'vacation' differ between different social groups. Its approach becomes a way of recognizing inequalities. This paper identifies the characteristics of the trips present in the biographies of the young people interviewed, the way they perceived those trips, the senses around them, as well as the enabling and limiting factors to undertake them. By analysing the narratives, it is possible to distinguish three types of trips: those possible and motivated by familiar bonds, those proposed by religious groups settled down in popular districts of the city for survival in the nature and those projected to future, as a desire of potential mobility.

Keywords: Child-youth tourism. Social inequality. Tourism and sociology.

\section{INTRODUCCIÓN}

En el campo de los estudios sociales centrados en las (in)movilidades espaciales se ha generado una mayor atención a las movilidades juveniles, por ejemplo, asociadas al uso y circulación por el espacio urbano, así como las vinculadas con las trayectorias migratorias, en tanto fenómenos que permiten advertir la complejidad y multidimensionalidad de los procesos de exclusión y desigualdad social (Gough \& Franch, 2005; Gough 2008; Saraví, 2014; Bastán \& Paulín, 2015; Chaves \& Segura, 2015).

A su vez, en el marco de las investigaciones en turismo se han comenzado a distinguir las particularidades de las prácticas turísticas juveniles. El aumento del número de jóvenes que circulan alrededor del mundo en el contexto de la globalización resulta uno de los principales argumentos utilizados para fundamentar dicho interés. Tal crecimiento es asociado, a su vez, a la creación de nuevos nichos turísticos juveniles -por ejemplo vinculados con los intercambios educativos, el voluntariado o el turismo backpacker- cuyo impacto es observado como significativo para el mercado turístico global. En su abordaje, estas maneras de viajar son entendidas como procesos generadores de autonomía e independencia y como oportunidades de aprendizaje y de conocimiento de nuevas culturas (De Castro \& Hidemi, 2010; Demeter \& Brătucu, 2014; Richards, 2015).

Ahora bien, la posibilidad de realizar este tipo de viajes o las características que 
pueden presentar, difieren significativamente entre las experiencias de los $^{2}$ jóvenes de distintos sectores sociales, regiones, etc. Como no resulta una práctica accesible para todos, indagar las (in)movilidades asociadas al vacacionar, y particularmente al viajar -interna o transnacionalmente-, se vuelve una forma de advertir las desigualdades sociales (Frändberg, 2009; Quinn \& Stacey, 2010; Schenkel, 2013).

En mi tesis doctoral ${ }^{3}$, a partir de los aportes de la sociología de la inviduación ${ }^{4}$ (Martuccelli, 2007; Araujo \& Martuccelli, 2012), me propuse identificar los principales desafíos emergentes en las biografías de jóvenes que desarrollaban actividades artísticas y deportivas gratuitas de barrios populares de la Ciudad Autónoma de Buenos Aires (CABA), los soportes que movilizan para enfrentarlos y el trabajo realizado sobre sí mismos para atravesarlos, analizando los espacios-tiempos y vínculos de relevancia para ellos.

Desde un abordaje cualitativo -observación y enfoque biográfico-, en el análisis, que siguió los lineamientos de la teoría fundamentada (Glaser \& Strauss, 1967), se iden- tificaron dos pruebas significativas en sus biografías: la prueba de relación con otros y las pruebas de las movilidades. En particular, ésta última remitía a las tensiones entre los deseos y motivaciones para salir de ciertos espacios y crear, ingresar y permanecer en otros. Ello suponía posibilidades y regulaciones para atravesar desde procesos migratorios y múltiples movilidades residenciales en búsqueda de bienestar y oportunidades laborales, hasta la circulación cotidiana por la ciudad para cumplir con obligaciones, como el estudio, el trabajo o el cuidado de otros, y el sostenimiento de las actividades artísticas y deportivas.

Dando continuidad a este análisis, en el marco de una beca posdoctoral procuro identificar otras experiencias de movilidad aún no exploradas en las biografías de estos jóvenes. En el presente trabajo se propone indagar: ¿Qué viajes realizan los/as jóvenes que residen en barrios populares de la CABA? ¿Qué características presentan estos viajes y cómo son percibidas por los jóvenes? ¿Cómo acceden a este tipo de desplazamientos? ¿Cuáles son las posibilidades o los obstáculos para realizar viajes que puedan ser asociados al 'vacacionar', a lo turístico? En función de

\footnotetext{
2 Teniendo conciencia de la orientación androcéntrica del español, utilizamos el género masculino sólo para facilitar la lectura.

${ }^{3}$ Título de tesis: “Cuerpos, emociones e individuación: un análisis de las experiencias de jóvenes que realizan prácticas artísticas y deportivas en barrios populares de la Ciudad Autónoma de Buenos Aires" (2016). Doctorado de la Universidad de Buenos Aires en Ciencias Sociales. Financiada por: Consejo de Investigaciones Científicas y Técnicas (CONICET), Argentina. Director: Dr. Pablo F. Di Leo. Co-director: Dr. Danilo Martuccelli.

4 La sociología de la individuación se plantea como un abordaje para "[...] reconstruir el carácter específico de una sociedad histórica a escala de sus individuos" (Araujo \& Martuccelli, 2012, p.15). Para ello, utiliza las nociones de pruebas y soportes como articuladores analíticos. La categoría de prueba refiere a la identificación de grandes procesos estructurales históricos, desigualmente distribuidos, por los que los individuos se ven obligados a atravesar. Los soportes sociales, de tipo material o inmaterial, es lo que permite a los individuos enfrentar tales desafíos.
} 
tales interrogantes, el objetivo es analizar los sentidos en torno al viajar y el vacacionar para identificar los tipos de viajes que se suceden en las biografías de jóvenes que residen en barrios populares de la Ciudad de Buenos Aires, el modo en que son percibidos y experimentados por éstos, así como los facilitadores y las limitaciones que encuentran los jóvenes para llevarlos a cabo.

Reconocer las movilidades e inmovilidades producidas requiere, asimismo, observar las intencionalidades y los potenciales desplazamientos de los jóvenes. Su lectura permite registrar las capacidades de ser móviles, así como a los deseos e intenciones de desplazarse o de permanecer -en sus vinculaciones con las prácticas que efectivamente son desarrolladas-, advirtiendo el modo en que tales capacidades se encuentran desigualmente distribuidas entre los diferentes grupos sociales (Kaufmann, Bergman, \& Joye, 2004; Clark \& Lisowski, 2016).

En el caso de los entrevistados, aun cuando se manifiestan dificultades económicas en diferentes momentos de sus biografías y las de sus familias, se realizan viajes que resultan acontecimientos de gran relevancia para ellos. De la lectura de los relatos se distinguen tres tipos de experiencias: a) viajes generados en el marco de los vínculos familiares, b) viajes asociados al acampar y a la supervivencia en la naturaleza, enmarcados en propuestas institucionales, y c) viajes deseados y proyectados a futuro.

La exposición del trabajo se organiza de la siguiente manera: primero, se reseñan algunos abordajes en torno a juventudes y turismo a partir de la lectura desde los estu- dios sobre juventudes y movilidades. Luego, se describe el enfoque metodológico que siguió esta investigación doctoral y en tercer lugar, se presenta el análisis de las experiencias juveniles a la luz de tres categorías construidas de los emergentes: los viajes familiares, los viajes de supervivencia y los viajes a futuro, que dan cuenta del modo en que se presentan estas movilidades en las biografías de los entrevistados. Finalmente, se plantean las reflexiones finales del trabajo.

\section{JUVENTUDES $Y$ TURISMO: DE MOVILIDADES E INMOVILIDADES}

Al hablar de juventudes debe advertirse que su definición alude a un proceso conflictivo en el establecimiento de los límites de su clasificación respecto de otros actores sociales. Lejos de ser una categoría autoevidente, refiere a una construcción relacional, social e histórica, y por lo tanto, dinámica y polisémica. No obstante, ciertos discursos institucionalizados y mediáticos han buscado homogeneizar y universalizar un único modo de ser joven: en transición, incompleto, desinteresado, problemático. En particular, invisibilizando las desiguales condiciones sociales y económicas de vida, son los jóvenes de sectores populares quienes resultan mayormente estigmatizados y estereotipados por estos discursos (Duarte Quapper, 2000; Chaves, 2005; Reguillo, 2012; Di Leo \& Camarotti, 2013; 2015).

A partir de la lectura de algunas investigaciones que abordan lo que se reconoce como turismo juvenil es posible advertir que éstas toman como punto de partida la definición establecida por la World Tourism Orga- 
nization (WTO, en Bizirgianni y Dionysopoulou, 2013):

\begin{abstract}
El turismo juvenil incluye todos los viajes de tipo independiente en períodos menores a un año, realizados por personas de entre 16 y 19 años, motivados, en parte o en su totalidad, por el deseo de experimentar otras culturas, crear experiencias de vida $y / 0$ beneficiarse de oportunidades de aprendizaje formales o informales por fuera del entorno habitual. (p. 654, traducción propia).
\end{abstract}

En dicha definición se destaca un tipo de viaje independiente realizado por un grupo establecido, básicamente, por la condición etaria. En dichos trabajos resultan escasas las discusiones acerca de lo juvenil y las implicancias del procesamiento social de las edades en nuestras sociedades, así como la diversidad y complejidad en el estudio de las experiencias juveniles que ello supone (Chaves, 2013; Demeter \& Brătucu, 2014). En términos metodológicos, muchos de estos estudios priorizan un abordaje cuantitativo, a través de la aplicación de encuestas o del análisis de datos secundarios producidos por la WTO y la Association of Tourism and Leisure Education (ATLAS).

Asimismo, se señalan las múltiples formas de viajar que llevan adelante los jóvenes y se identifican los nuevos enclaves y nichos turísticos conformados en los procesos de segmentación emergentes en el marco de las demandas turísticas actuales. Esto es, la conformación de sectores de usuarios distinguidos por ciertas características o preferencias, así como por sus condiciones sociales y culturales (Ansarah \& Panosso Netto, 2009, p. 20, citado por de Cas- tro \& Hidemis, 2010, p. 7). En ese sentido, resulta interesante la tipología propuesta por Demeter \& Brătucu (2014), en la que distinguen las modalidades de viajes, individuales o facilitadas por programas institucionales, más frecuentes entre los jóvenes europeos: las de tipo educativo, los intercambios culturales, el voluntariado, los viajes de trabajo, las asociadas al deporte y al turismo aventura, o al ocio y la recreación (p. 116). En función de esta categorización es posible advertir que la producción académica en el campo del turismo juvenil ha seguido una diferenciación similar en la definición de sus objetos de estudio donde, entre otras, se registran investigaciones sobre el backpacking, el voluntariado, los viajes educativos o los recreativos (Richards \& Wilson, 2003; Gallegos Granero, Ruiz, \& García Montes, 2005; Laborda, 2007; Morgan \& Xu, 2009; Lyons, Hanley, Wearing, \& Neil, 2012; Cavagnaro \& Staffieri, 2015).

Entre los núcleos más estudiados el viaje de tipo backpacker (o mochilero), y sus múltiples versiones actuales, así como los enclaves emergentes en torno a estos, es reconocido como una de las formas pioneras que adoptó el turismo joven. A diferencia de gran parte de las investigaciones que utilizan encuestas para indagar el vínculo entre juventudes y turismo, en los estudios sobre backpackers, resultan más frecuentes los abordajes etnográficos. Se destaca la investigación de Greg Richards (2015: 344) quién, del análisis de las asociaciones entre el pensamiento 'nómade' y el análisis del turismo backpacker, propone una comparación con nuevos viajeros, los flashpackers y los nómades glo- 
bales en sus motivaciones para viajar, las actividades que realizan y el modo en que se configuran sus identidades en torno a éstas. Abordar estas nuevas movilidades, subraya el autor, requiere reconocer la diversidad que plantean los viajes que realizan los jóvenes en la actualidad y de ahí, sus múltiples abordajes.

Otro aspecto relevante ha sido el análisis del vínculo entre las características del turismo juvenil y el uso de las nuevas tecnologías (TICs) y las redes sociales. Al ser los jóvenes sus principales usuarios, se presentan como dimensiones sustantivas para la comprensión de sus prácticas turísticas como la planificación de itinerarios, la comunicación durante los viajes o una vez que éstos han finalizado (Grellmann \& Pozobon, 2010; Bizirgianni \& Dionysopolou, 2013).

Por último, otras investigaciones han destacado las desigualdades de las movilidades turísticas juveniles según los lugares de residencia, las condiciones de vida o los orígenes étnicos de cada joven y sus familias. Así, por ejemplo en el estudio de Lotta Frändberg (2009), frente a las imágenes que presentan las movilidades transnacionales como prácticas 'normales' y 'necesarias' en los países más ricos, se plantean, en cambio, las desiguales posibilidades de movilidad física entre los grupos de jóvenes suecos en función del sector social de pertenencia, el origen étnico o su residencia en el ámbito urbano o rural. En base a tales constataciones, la autora señala que la movilidad transnacional resulta un crítico factor diferenciador entre los jóvenes.

Si bien algunos abordajes exaltan como positiva la libertad para moverse, aso- ciando lo móvil con la tendencia a cambiar fácil y rápidamente, o priorizan los flujos, la velocidad, por sobre lo fijo y lo estable, resulta preciso poner en cuestión los sentidos que invisibilizan las condiciones que impulsan o limitan las movilidades. Frente a tales perspectivas, se vuelve sustantivo reconocer las relaciones de poder y dominación que producen y son producto de desigualdades en las cuales se (re)crean (in)movilidades, ya sean potenciales o efectivas (Sheller \& Urry, 2006; Cresswell, 2010; Sheller, 2014). Deviene relevante considerar esta potencialidad de los desplazamientos para identificar los márgenes de maniobra de los individuos en sus vidas cotidianas, es decir, para poner en práctica su capacidad de ser "móviles", así como las consecuencias sociales, económicas y simbólicas que esto conlleva (Kaufmann et al., 2004). En particular, es posible pensar el turismo como una forma de movilidad que se conforma a partir de diferentes (in)movilidades - de personas, de objetos, de información-, que supone prácticas que construyen y reconstruyen lugares establecidos como destinos turísticos, pero también:

Turismo se relaciona con las movilidades
que vinculan memorias y performances,
cuerpos genéricos y racializados, emo-
ciones y atmósferas. Las movilidades tu-
rísticas incluyen complejas combinacio-
nes de movimiento y detenimiento,
realidades y fantasías, juego y trabajo.
(Sheller y Urry, 2004, p. 1, traducción
propia).

Debe advertirse que la posibilidad de vacacionar y las prácticas asociadas a ello no resultan igualmente accesibles a todos los grupos sociales. Contar con un período de 
descanso, incluso cuando éste sea pago, no se traduce necesariamente en un acceso al turismo. Esta posibilidad varía de acuerdo con los ingresos, el tiempo disponible, la edad, el género, condiciones étnicas y de nacionalidad, las enfermedades y discapacidades, la estructura de acceso a un período vacacional y las oportunidades para viajar (Quinn \& Stacey 2010; Frändberg, 2013; Schenkel, 2013).

\section{METOdOLOGÍA}

Esta investigación doctoral se desarrolló desde un abordaje cualitativo situándose, en particular, en el marco del paradigma interpretativo (Vacilachis, 2012) ${ }^{5}$ que se propone "comprender el sentido de la acción social en el contexto del mundo de la vida y desde la perspectiva de los participantes" (Vacilachis, 2009, s/p). Busca privilegiar en sus análisis lo profundo, lo intenso, lo particular por sobre lo superficial, lo extenso y las generalidades.

El trabajo de campo fue realizado durante el segundo semestre del año 2014 en una organización social (en adelante "el circo"6), que funciona en Buenos Aires desde el año 1998 y cuyo propósito es contribuir a la transformación personal, comunitaria y social a través del arte. Durante el trabajo de campo, la organización contaba con cuatro sedes (en la actualidad funcionan en dos sedes diferentes). Allí se ofrecen talleres artísticos gratuitos como artes circenses, hip-hop, maquillaje artístico, teatro o kung-fu. La participación de los jóvenes en los talleres se produce a partir de la inscripción en el Programa Adolescencia ${ }^{7}$, un programa municipal de la CABA, o bien, como 'invitados' a partir de la relación con otros jóvenes concurrentes o su acercamiento directo al espacio.

Con acuerdo de los integrantes de la institución, siguiendo la estrategia de participación-observación y el registro en un diario de campo, asistí a cuatro talleres durante el segundo semestre del año 2014: trapecio y tela; acrobacia y malabares; hip-hop y tango, que se desarrollaban en tres de las cuatro sedes del circo. En tanto técnica de investigación social, la observación se consideró una herramienta relevante para producir conocimiento del espacio en el que participaban los jóvenes con quienes interesaba, además, entrar en contacto para la construcción de relatos biográficos (Scribano, 2008).

De este modo, en articulación con el proceso de observación, se desarrolló un enfoque biográfico que consiste en recuperar la narrativa de las experiencias de una persona a lo largo del tiempo con el fin de elaborar, a través de entrevistas sucesivas, un relato (Leclerc-Olive, 2009; Di Leo \& Camarotti, 2013; 2015). Se propuso así la construcción

\footnotetext{
${ }^{5}$ Aquí se sigue la propuesta analítica de Irene Vacilachis (2012: 46-47), quien define paradigmas como “(...) los marcos teórico-metodológicos utilizados por el investigador para interpretar los fenómenos sociales en el contexto de una determinada sociedad".

6 "El circo" es el modo en que quienes participan del espacio denominan cotidianamente a la institución.

${ }^{7}$ El programa depende de Niñez y Adolescencia, del Ministerio de Desarrollo Humano y Hábitat del Gobierno de la Ciudad de Buenos Aires:

http://www.buenosaires.gob.ar/desarrollohumanoyhabitat/ninezyadolescencia/adolescencia
} 
de relatos biográficos con jóvenes a partir de la realización de una serie de entrevistas semi-estructuradas que, en tanto instancias dialógicas, permitieron indagar el modo en éstos construyen sus experiencias, sus vínculos, situaciones conflictivas o cambios en sus vidas cotidianas (Souza Minayo, 2007).

En el marco del abordaje cualitativo e interpretativo propuesto se siguieron los lineamientos de la teoría fundamentada para el desarrollo del análisis y el establecimiento de la muestra. Desde esta perspectiva el muestreo teórico “(...) se realiza para descubrir categorías y sus propiedades, y para sugerir las interrelaciones dentro de una teoría" (Glaser y Strauss, 1967: 62 citado en Soneira, 2012: 155). Así, la selección de los casos incluidos se sustentaba en su potencialidad para contribuir a la generación de nuevas categorizaciones o ampliar las ya producidas. Su delimitación se basaba en el criterio de saturación teórica, esto es, ante la inclusión de un nuevo caso se advierte que éste ya no per- mite suministrar información adicional para la construcción de nuevas categorizaciones.

Se entrevistó - previo consentimiento informado-, a 7 varones y 4 mujeres, de entre 18 y 24 años, residentes en barrios populares de la CABA y que participaban en alguno de los talleres con al menos un año de antigüedad (Ver Tabla I). Tales barrios -donde se ubicaban también las sedes del circo- se sitúan al sur de la CABA, en áreas de mayor empobrecimiento urbano, especialmente en viIlas. Éstas refieren a urbanizaciones informales resultantes de ocupaciones de terrenos vacantes o privados, deshabitados o baldíos. Registran alta densidad poblacional, viviendas construidas con materiales precarios y escaso acceso a servicios públicos o espacios verdes y/o recreativos. Sus habitantes, en su mayoría trabajadores informales o con baja calificación, suelen ser estigmatizados socialmente (Cravino, Del Río, \& Duarte, 2008). 
Tabla 1 - Datos de los jóvenes entrevistados

\begin{tabular}{|c|c|c|c|c|c|}
\hline Seudónimo ${ }^{8}$ & Edad & Ocupación & Nivel de escolaridad & Lugar de nacimiento & Hijos \\
\hline Iván & 23 & Trabajos informales & Terciario en curso & Provincia de Salta & No \\
\hline Omar & 20 & Trabajos informales & Secundario incompleto & Buenos Aires & No \\
\hline Gustavo & 20 & No trabaja & Universitario en curso & $\begin{array}{l}\text { Buenos Aires } \\
\text { (Madre Bolivia) }\end{array}$ & No \\
\hline Lolo & 18 & No trabaja & Secundario en curso & $\begin{array}{l}\text { Buenos Aires } \\
\text { (Padres Bolivia) }\end{array}$ & No \\
\hline Portal & 18 & No trabaja & Secundario en curso & $\begin{array}{l}\text { Buenos Aires } \\
\text { ( Padres Provincia de Jujuy) }\end{array}$ & No \\
\hline Sofía & 18 & No trabaja & Secundario completo & Buenos Aires & No \\
\hline Chinita & 20 & $\begin{array}{l}\text { No trabaja } \\
\text { (cuida a su hermana) }\end{array}$ & Universitario en curso & $\begin{array}{l}\text { Buenos Aires } \\
\text { (Madre Paraguay) }\end{array}$ & No \\
\hline Romina & 19 & No trabaja & Secundario completo & Buenos Aires & No \\
\hline Edrul & 19 & $\begin{array}{l}\text { Trabaja en taller fami- } \\
\text { liar }\end{array}$ & Secundario incompleto & Bolivia & No \\
\hline Solanch & 20 & Trabaja & Secundario completo & Paraguay & Si \\
\hline Mateo & 23 & $\begin{array}{l}\text { No trabaja } \\
\text { (busca trabajo) }\end{array}$ & Secundario completo & Buenos Aires & No \\
\hline
\end{tabular}

Fuente: elaboración propia

Los jóvenes fueron contactados a partir de la participación en los talleres, no obstante las entrevistas se desarrollaban mayormente por fuera de los espacios institucionales. Con cada joven se realizaron entre 3 y 7 encuentros (en total 48 entrevistas). Para iniciar las entrevistas, éstos identificaban los acontecimientos que hubieran establecido un giro existencial en sus vidas, es decir, eventos, situaciones, relaciones, que ponían de manifiesto turning points, momentos claves que establecieron un antes y un después en sus vidas. En ese sentido, “(...) un acontecimiento se convierte en biográficamente significativo, por el hecho de obligar a reelaborar un relato de la vida: de esta forma, el acontecimiento es objeto y detonante del relato" (Leclerc, 2009: 3). En la segunda entrevista, se solicitaba que llevaran objetos como fotografías o recuerdos, que se vincularan a esos momentos significativos seleccionados por cada joven. A partir de extractos de las desgrabaciones de los audios de las entrevistas y de la selección de acontecimientos se co-construía un relato escrito de forma consensuada entre investigadora y entrevistados, que daba lugar al encadenamiento de momentos relevantes que conformaban una temporalidad singular, no lineal ni unívoca (Leclerc, 2009, Di Leo y Camarotti, 2013).

Para su análisis, siguiendo los lineamientos de la teoría fundamentada, se utilizó

\footnotetext{
${ }^{8}$ Se utilizan seudónimos elegidos por los jóvenes entrevistados durante la construcción de los relatos.
} 
como auxiliar la herramienta de software Atlas.ti. Allíse identificaron como emergentes en los relatos los términos asociados a "viajar" y a las "vacaciones". Del diálogo entre la bibliografía, también de carácter emergente y los datos empíricos construidos, se establecieron tres categorías en torno a las experiencias asociadas al viajar de los entrevistados: los viajes familiares, los viajes de supervivencia y los viajes a futuro, que se presentan a continuación.

\section{RESULTADOS Y DISCUSIÓN}

\subsection{Los viajes familiares: de encuentros y desencuentros}

Una de las formas de viajar que se vislumbró en los relatos se relaciona con la visita a familiares durante períodos vacacionales. Gran parte de estos viajes se vincula con la movilidad migratoria que llevaron adelante los jóvenes y sus familias, especialmente durante su niñez. En algunos casos se trataron de desplazamientos desde otras provincias de Argentina o de países de la región, como Bolivia y Paraguay, hacia Buenos Aires, en búsqueda de mayor bienestar asociado a lo laboral, la vivienda y lo educativo. Luego de dichos traslados, donde estas familias se asientan finalmente en la CABA, el vínculo con la familia extendida se procura sostener a través de los viajes realizados durante las vacaciones de verano que, en Argentina, generalmente se ubican entre los meses de diciembre, enero y febrero.

Diversos autores han sugerido la necesidad de considerar lo migratorio y lo turístico desde sus vinculaciones. En tanto movili- dades no secuenciales o lineales, no refieren a un movimiento desde un lugar fijo de origen a otro destino único final, sino a prácticas que son dinámicas, simultáneas y fuertemente interconectadas. Un aspecto especialmente considerado en esta relación ha sido lo étnico. Su análisis ha sugerido el modo en que la ocurrencia de viajes temporarios son muchas veces motivados por los reencuentros con las historias familiares y comunitarias, como una forma de reafirmar y recrear lo heredado, lo identitario (Timothy \& Coles, 2004; Glick Shiller \& Salazar, 2013; Schrooten, Salazar, \& Dias, 2015).

Para los entrevistados, en su niñez y en la actualidad, las vacaciones suponen la posibilidad de visitar y conocer a otros integrantes de sus familias, así como los lugares en los que éstos residen. En ciertos casos, incluso habilitan el primer encuentro con estos familiares. Lolo, de 18 años, reside en una de las villas de la ciudad junto con su familia. Su madre siendo joven migró desde Bolivia. Luego de su viaje a la CABA perdió contacto con uno de sus hermanos a quién, reencontró años más tarde en Córdoba, otra provincia argentina, a quién Lolo también conocerá al viajar hasta allí:

Los momentos que vivíallá, las poquitas semanas que viví allá y fue muy lindo, me encariñé mucho con ellos, fue como mucho, mucho más rápido de lo que yo había pensado. Y cuando tuve que volver fue como... i"no me quiero ir"! (Lolo)

Para Lolo la visita a su tío y su familia otorga la oportunidad de conocerlos, estableciendo un vínculo que durante el año se sostiene a través de las redes sociales. Y, en el verano, se vuelve un lugar al que se retorna 
con ansias. Iván, otro entrevistado de 23 años, reside actualmente con sus padres y hermanos en una vivienda propia en el barrio del sur de la ciudad. Antes de su llegada a Buenos Aires, ellos vivieron en varias provincias del norte argentino. Para él, las vacaciones de su niñez están asociadas a estos lugares donde continuaban residiendo sus primos, tíos y abuelos:

Antes cuando era chico me iba 2 meses de vacaciones (...) a los 7, 8, nos juntamos de nuevo con mis primos y también era mejor porque íbamos todos juntos (Iván)

En los relatos estos viajes potencian el reencuentro con sus familiares $y$, a su vez, se relacionan con una posibilidad de vacacionar que produce disfrute y bienestar. En un estudio sobre el turismo de jóvenes descendientes de japoneses residentes en São Paulo, Brasil - a partir de la aplicación de una encuesta a jóvenes de sectores medios, entre 15 y 30 años - se advierte que, si bien los viajes vinculados al ocio y al placer son sus principales motivos de desplazamiento, el 'turismo sociofamiliar' también deviene relevante. En efecto, es la visita a familiares y amigos lo que resulta una de las razones más mencionadas para llevar adelante viajes en períodos vacacionales, aspecto asociado al valor significativo que adquiere la familia en la comunidad japonesa y su influencia al momento de tomar decisiones sobre los destinos o características de los viajes vacacionales (de Castro \& Hidemi, 2010).

Estos viajes, aún vinculados con lo familiar, comienzan a experimentarse de modo diferente a medida que los jóvenes crecen. La posibilidad de movilizarse solos, sin la compañía de adultos, permite experimentar situaciones novedosas y desafiantes. Gustavo, de 20 años, si bien siendo niño viajó en varias ocasiones a Bolivia -donde había nacido su madre y dónde aún vivían su abuela y sus primos- al viajar por primera vez solo, las sensaciones son diferentes:

(...) Sentí como un mini cambio. Sentí como esa independencia de que me habían dado una responsabilidad (...) Tengo que bajar en cada parada y que tengo que estar atento de que no se vaya el micro, que tengo que comer algo, tengo que sobrevivir todo ese día (...) Tomar otro micro, porque te deja en un lugar en Jujuy, tenés que tomarte otro micro hasta la frontera. Después de ahí te tenés que tomar un taxi todo por Bolivia, te deja en la terminal, tenés que llegar a lo de mi abuela. Supongo que habrá sido fuerte para mi mamá y mi papá, pero sí, es verdad, ahí sentí como que cambió, como que me estaban soltando (...) Nunca había viajado solo porque el único viaje que tenía era hasta la facultad o hasta la secundaria, no tenía más que eso (Gustavo)

La posibilidad de viajar solo para visitar a su abuela se manifiesta como una responsabilidad ganada, pero que, al mismo tiempo, habilita su independencia. Un "cambio" en el vínculo con los padres y a la vez, en sus desplazamientos cotidianos. No viajar acompañado no es lo único que genera tales sensaciones. La distancia y el tipo de traslado requerido para llegar hasta el lugar en que reside su abuela también revela un aprendizaje como viajero: estar atento a los horarios, a la combinación de diferentes transportes, a la alimentación.

Algunos viajes juveniles se asocian a 
prácticas experimentadas como 'ritos' de pasaje, en los que ciertas modalidades, momentos o lugares elegidos, establecen un paso a la 'adultez' traducido en mayor autonomía y libertad. Así por ejemplo, se señala el modo en que los backpackers, especialmente los varones, utilizan esta práctica para convertirse en jóvenes adultos (Noy, 2004; MartínCabello, 2014). En un sentido similar, en un estudio acerca de la celebración de las 'Quinceañeras' (15 años) en los sectores altos peruanos, los viajes al exterior contribuyen a reactualizar esta tradicional celebración que expresa la salida de la infancia. Allí, el regalo de un viaje al exterior, supone para las jóvenes su primera separación de sus familias y la posibilidad de ser autónomas por primera vez (Cavagnoud, 2012).

En el contraste entre los recorridos urbanos habituales y los producidos en las vacaciones familiares, para Portal, de 18 años, cada verano genera en él transformaciones significativas en sus modos de ser: "allá soy otra persona". Viajar al lugar donde residen sus primos y tíos en la provincia del norte de Argentina, Jujuy, permite conocer otras personas, e incluso, tener "relaciones de pareja", algo que no ha sucedido en Buenos Aires. Al preguntarle por el modo en que percibe esta diferencia, manifestaba:
(...) es que allá soy otra persona comparado con acá. Por ahí allá como que, como al estar con primos, con gente que hace mucho tiempo que no veo, viste, una parte como que saco, soy el doble de carismático (...) voy con otra mentalidad allá, voy con la mentalidad diciendo, estoy en otro lugar y voy a ir en poco tiempo... no me preocupo tanto en lo que voy a decir o en que es lo que puede pasar (...) En cambio acá voy a estar casi todo un año seguido y hasta entonces, quiero ser la persona que soy todos los días, no quiero que un día sea diferente comparado a los demás (Portal)

La distancia que implica estar en un espacio diferente a lo cotidiano, así como la duración que ello supone, permiten ser "otro". En este período es posible "pasarla bien", no preocuparse, tener "otra mentalidad". De este modo, vacacionar está asociado a lo familiar, pero también, a la posibilidad de conocer personas y configurar una experiencia de disfrute y placer que sólo este viaje habilita.

\subsection{Viajes de supervivencia: las experiencias en los campamentos scouts}

Otros tipos de viajes emergentes en los relatos fueron los surgidos de la participación en los grupos scouts ${ }^{9}$, agrupaciones en su mayoría vinculadas a

9 “La Misión del Movimiento Scout es contribuir a la educación de los jóvenes a través de un sistema de valores basado en la Promesa y la Ley Scout, para ayudar a construir un mundo mejor donde las personas se desarrollen plenamente y jueguen un papel constructivo en la sociedad. Esta Misión se logra: Comprometiendo a los jóvenes durante sus años de formación en un proceso de educación no formal. Utilizando un método específico que hace de cada joven, principal agente de su desarrollo, una persona segura de sí misma, solidaria, responsable y comprometida. Ayudando a los jóvenes a establecer un sistema de valores, basado en principios espirituales, sociales y personales como se expresan en la Promesa y la Ley Scout" (https://www.scouts.org.ar). 
iglesias católicas $^{10}$ situadas en los barriosdonde residen los jóvenes. Entre las actividades que proponen se encuentran los campamentos para lo cual se realizan viajes a diferentes lugares dentro del país, donde se ponen en práctica técnicas de supervivencia en hábitats naturales.

En las biografías de los jóvenes, estas experiencias permiten conocer otras ciudades, en algunos casos, reconocidas como destinos turísticos argentinos. Sin embargo, el tipo de viaje realizado no supone recrear los circuitos turísticos habituales, sino que plantean el desafío de atravesar condiciones adversas como la falta de agua corriente, baños u hospedajes poco confortables. Para dos de los jóvenes entrevistados que participaron de dichas agrupaciones, esto ha sido experimentado de manera muy diferente.

Chinita, de 20 años, reside en una de las villas de la CABA, junto con su familia. A través de una beca, estudia psicología en una universidad privada muy reconocida de la ciudad. Cuando todavía se encontraba en la escuela secundaria, cinco años atrás, a partir de la concurrencia a una de las iglesias de su barrio, había comenzado a participar del grupo de scouts que allí funcionaba. En dicho contexto, se establece la oportunidad de realizar el primer viaje. Al recordarlo mencionaba:

Yo pensaba que me podía adaptar a cualquier situación, pero el hecho de viajar a un lugar y vivir en el medio de la nada, sin una cama, un colchón, internet, celular, música, tecnología, me afectó, o sea, me cambió [¿qué expectativas tenías antes de ir?] que me iba de vacaciones. Que iba a ir a un departamento, a una cabaña, no sé, que por lo menos un colchón y una cama iba a haber, un cargador, algo! Entonces es como que ir con todo un plan y llegar ahí $y$ que te lo cambien es como que me cayó medio mal (...) disfrutaba de la naturaleza, pero me hubiera gustado disfrutarla más estando en una cabaña, pudiendo salir a caminar tranquilamente (Chinita)

La distancia entre las expectativas y lo ocurrido resulta muy significativo para Chinita. A la idea de vacaciones con comodidades y amenities, se contrapone una experiencia muy diferente en esta propuesta donde la finalidad no es el turismo, sino el aprendizaje de la supervivencia y el encuentro con la naturaleza y lo espiritual. En un estudio cualitativo se analiza un proyecto en Rio de Janeiro que ofrece a jóvenes de bajos recursos la oportunidad de conocer puntos turísticos de la ciudad. Sus organizadores lo proponen como un espacio que promueve la concientización del derecho al uso y disfrute de la ciudad -en menor medida que lo recreativo-, dando lugar, incluso, a la primera oportunidad de experimentar una práctica túristica para los jóvenes. Sin embargo, éstos no logran percibir los paseos y las actividades como turismo o como una práctica recreativa. De modo similar, para Chinita si bien se

10 La Iglesia Católica en Argentina tiene una larga trayectoria de intervención en distintas áreas sociales orientadas a la población de los barrios populares de Buenos Aires (Esquivel, 2000). 
habilita la posibilidad de viajar y conocer nuevos lugares, no significa que sea disfrutado por ella.

Mateo, de 24 años, hasta sus 18 años residió en hogares para niños, debido a un conflicto de violencia familiar que lo separó de sus padres y hermanos. En la concurrencia a una iglesia católica durante esos años, comienza a participar de un grupo scout:

(...) hacen campamentos en verano y en invierno, y con ellos me fui a todos lados. Me fui a Córdoba, me fui a Neuquén, me fui a San Martin de los Andes que está también ahí, me fui a Misiones, a Corrientes, a todos lados. Hice supervivencia, que estamos en carpas, no estábamos en casas. Se alquila, cómo se dice... un country, algo así, pero todo bosque, todo, todo bosque, como un camping (...) se hace el fuego, se instala la carpa, hacemos el leñero, después está el aguatero y así (...) Para mí un gran placer y un orgullo de compartir esos momentos con los chicos, de los scout que fue algo nuevo en mi vida digamos. Me abrió muchos lugares, las puertas, conocí como muchos sitios, conocí muchos pueblos, hice muchos servicios, de todo un poco y fue re linda esa etapa (Mateo)

En el relato de Mateo se destaca la diversidad de lugares que tiene la oportunidad de conocer a partir de la participación en dicho grupo, así como las tareas que suponen estos tipos de viajes donde también se ponen en juego valores cristianos como el servicio y la solidaridad. En el estudio del turismo juvenil los viajes asociados a la supervivencia en la naturaleza fueron asociados a la búsqueda de emociones y aventuras (De Castro e
Hidemi, 2010). Sin embargo, ser joven no supone necesariamente que todos experimenten tales prácticas de la misma manera. Por el contrario, de los relatos aquí citados se advierte que viajes tan similares como los mencionados, ponen de manifiesto sensaciones y expectativas muy disímiles: desde el disfrute, el interés, el orgullo que produce en Mateo, frente a los nervios e incomodidades que experimenta Chinita.

No obstante, si bien los dos entrevistados perciben estos viajes de manera tan diferente, en la (re)construcción de sus relatos biográficos, estas experiencias resultan muy significativas. Fue llamativo que, por ejemplo, en ambos casos al seleccionar objetos personales que les permitieran recordar momentos de cambio relevantes en sus vidas, la elección de objetos y fotografías hacían referencia, mayormente, a estos viajes y a lo que éstos habían habilitado: conocer personas, visitar nuevos lugares.

\subsection{Los viajes a futuro: entre lo deseado y lo posible}

Como se mencionara al inicio, atender a las movilidades e inmovilidades no sólo refiere a las prácticas efectivas, sino también a las potenciales y a la capacidad de (in)movilidad de las personas. Andrea Gutiérrez (2013) -siguiendo los aportes de Kaufmann (2002) y Hernández (2012) citados por la autora- señala las vinculaciones entre los conceptos de motilidad y accesibilidad para pensar las movilidades. En tanto la motilidad refiere a la potencialidad de los movimientos como capacidad personal y como capital so- 
cial para ser móviles de los individuos, la accesibilidad permite pensar, además, la interacción entre las estructuras de oportunidaddes para dicha movilidad y los recursos, soportes y activos de los individuos y las familias para hacer uso de tales oportunidades. En este sentido, la potencialidad resulta central para advertir que "la accesibilidad (y la movilidad) es un capital vinculado con la capacidad de llegar a lugares" (p. 64).

En el marco de la construcción de sus relatos biográficos resultó significativo que, al preguntar a los jóvenes por una visión de su futuro y del modo en que imaginaban y deseaban que fuera su vida en los próximos diez años, entre sus principales expectativas como el trabajo, la vivienda y la familia, varios de los jóvenes mencionaron el deseo de "viajar, viajar, viajar". Sofía, una de las entrevistadas de 18 años vive en una de las villas de la CABA junto con su madre y su hermano. Se encuentra finalizando la escuela secundaria, en una reconocida institución de dicha ciudad, y aspira a estudiar ingeniería posteriormente. En su relato se expresaba el deseo de viajar una vez finalizados sus estudios:

Y después bueno, viajar, nada más, viajar... y después, después de muchos años de haber viajado y haberla pasado re bien, re bien, tener una familia, pero eso ya después, re secundario (...) pero sí me veo así viajando, con un laburo fijo o con una casa, ya propia, con mi mamá en otra casa propia de ella, fuera de esa zona, digamos, en un lugar tranqui... (Sofía)

Viajar se manifiesta como una experiencia que se opone a la generación de un proyecto de familia, que no resulta del todo deseado para la joven, al menos no antes de alcanzar otras metas como las profesionales, la de una vivienda propia fuera de la villa y también, la de viajar. Por su parte, en su relato, para Mateo lo que se proyecta a futuro es lograr "ser profesor, dar clases, tener un hijo, formar una familia, por ahí casarme, no se todavía, tener una casa", pero también, "viajar y viajar". Realizar un viaje se vincula así con prácticas que en el presente aún no se vislumbran del todo posible, sino que requieren de tiempo e instancias previas como el estudio y el trabajo, para poder llevarlas a cabo. En su investigación sobre "O Lazer Brasileiro", Edmur Stoppa, Luis Gonzaga Godoi Trigo y Helder Ferreira Isayama (2017), a partir de un abordaje cuali-cuantitativo a nivel nacional proponen estudiar las significaciones acerca de las prácticas turísticas asociadas al ocio y el tiempo libre en los períodos vacacionales. Allí, destacan las importantes distancias entre los deseos e intenciones y la experiencia efectiva de vacacionar. En ese sentido, advierten que debido a los costos económicos que suponen las prácticas turísticas y su accesibilidad limitada para el conjunto de la población brasilera, aquéllas resultan más un deseo, que una vivencia que puede concretizarse (p. 144).

En el relato de Gustavo, el ideal futuro se aproxima a la experiencia del viaje de mochilero. Así, entre sus principales deseos para un futuro no tan lejano, imagina una forma de viajar que debiera presentar características específicas:

(...) ahora estoy pensando de salir de mochilero con mi amigo (...) me gustaría salir y ver qué onda, conocer gente, ver 
cómo sobrevive, esas cosas. Sería una experiencia de la cual aprendería mucho [¿cuál es tu idea?] Conocer cómo es la gente de otros lugares (...) A veces vamos con el coche de mi papá y veo que es distinto, pero ya hacerlo a mi manera, parando lo que yo quiera en cada pueblo, de ir a un pueblo chiquito y que sea tranquilo, ponele a mí no me gusta lo que es ruidoso, lo que es multitud (...) me gustaría tipo a un pueblo así tranquilo y ver cómo es la vida, cómo es lejos de toda la gente acá muy citadina, ahora salís y hay un montón de trenes, colectivos, de gente que pasa, que se empuja (Gustavo)

En los abordajes de los viajes de tipo backpacker - mochilero - esta modalidad ha sido incluso identificada como una 'subcultura juvenil' (Martín-Cabello, 2014), dadas las particularidades que se le atribuyen: la búsqueda de lo auténtico y lo genuino en los lugares explorados; la búsqueda de libertad y el rechazo al materialismo; la búsqueda de aventuras y un camino propio (Noy, 2004; Martín-Cabello, 2014; Richards, 2015). Ser mochilero habilitaría para Gustavo la oportunidad de sobrevivir, conocer gente en lugares menos poblados y sus modos de vida, alejados de la ciudad y sus ruidos, sus ritmos. Una experiencia que se asocia, fundamentalmente, a un aprendizaje que sólo sería posible a través de este tipo de viaje. Asociado a la idea de un "mochilero", para Gustavo ello significaría mayor libertad y la posibilidad de despejarse, conocer otros lugares, "hacerlo a mi manera".

El deseo de viajar se hace presente en los relatos de los jóvenes y, al mismo tiempo, se pone de manifiesto el contrapeso ante la necesidad de cumplir con el deber de estudiar, de trabajar y el anhelo de la vivienda propia, no sólo para ellos, sino también para los integrantes de sus familias. El turismo en Argentina, si bien ha sido reconocido como un derecho de las personas para disfrutar de esta práctica de manera equitativa, para una parte significativa de la población no ha sido posible hacerlo efectivo, fundamentalmente por cuestiones económicas. Como señala Érica Schenkel (2013), a partir de datos estadísticos, "(...) a medida que se desciende en la escala de ingresos son menores las proporciones del presupuesto familiar que se destinan a prácticas turísticas y recreativas, debido a que existen necesidades más urgentes a satisfacer" (p. 198).

En el caso de los jóvenes entrevistados, aun cuando las condiciones de vida actuales no sean las más favorables y la visión del futuro esté asociada al cumplimiento de obligaciones como las vinculadas con lo laboral y lo educativo, resulta significativo que los jóvenes, de todos modos, proyecten la posibilidad de viajar como deseo de movilidad futura, como momento de disfrute y descanso, en tanto que: "Disfrutar de un placer descomprometido puede ser mejor cuando se lleva a cabo en un espacio diferente del cotidiano, sistemático y muchas veces, monótono" (Stoppa, Godoi Trigo e Isayama, 2017, p. 144, traducción propia).

\section{REFLEXIONES FINALES}

Analizar las prácticas turísticas, considerando las articulaciones entre las condiciones estructurales y subjetivas, permite entrever las desigualdades expresadas en las (in)movilidades. Las oportunidades y las limi- 
taciones para viajar no son posibles de anticipar solamente en función de las posiciones sociales o por la condición etaria. En este trabajo fue posible identificar los modos en que, aun experimentando dificultades económicas, los jóvenes de barrios populares de la CABA han viajado en distintos momentos de sus biografías y ello ha provocado giros significativos en sus vidas. En el análisis de sus relatos se distinguen tres modalidades de viaje: familiares, de supervivencia y a futuro.

Los jóvenes sostienen vínculos a distancia, en forma virtual, pero también a partir de viajes que resultan muy valorados por ellos. Los viajes familiares, como señalan otros estudios, expresan las vinculaciones entre las movilidades migratorias y las turísticas, donde se advierten múltiples traslados que posibilitan encuentros y reencuentros con la familia extendida y, a su vez, conocer los lugares en los que éstos residen. Los jóvenes perciben dichos viajes como vacaciones, asociadas al disfrute y a la oportunidad de cambiar. La posibilidad de viajar solos les otorga responsabilidades, pero también, les permite ser más independientes y acceder a nuevas experiencias, que contrastan con las vividas al viajar junto a sus padres y a las de su cotidianeidad en la ciudad.

Es, también, a través de instituciones como las agrupaciones scouts, que viajar se vuelve posible, aunque de manera más regulada. Son viajes que suponen adaptarse a una rutina laboriosa y alejada de comodidades asociadas a una estadía turística. Si bien habilitan la posibilidad de visitar lugares, que de otra manera no sería posible conocer para estos jóvenes, no necesariamente generan sensaciones positivas en ellos. No obstante, provocan recuerdos valorados y marcan momentos de cambio significativos.

Las estadísticas han manifestado las distancias en la accesibilidad para vacacionar entre sectores con diferentes ingresos. Sin embargo, aun con dificultades económicas, los viajes aparecen en los relatos, de modo potencial, como una manera de imaginar el futuro deseado. Junto con otros proyectos como la vivienda propia, el trabajo soñado y la finalización de los estudios secundarios, viajar se asocia a lo que, como adultos, desearían experimentar. Sin embargo, parece más difícil distinguir las posibilidades concretas de llevarlos a cabo, o incluso, realizarlos en un futuro más cercano. Asimismo, estos deseos entran en tensión con los ideales de progreso a los que estos jóvenes deben responder: discursos sociales que suelen estigmatizarlos como vagos o problemáticos, o que buscan asimilarlos a los jóvenes de clases medias y altas que son presentados como jóvenes despreocupados y libres.

Reconocer el carácter situado del análisis de las juventudes - su diversidad, su multiplicidad, sus tensiones - al hacer referencia a sus experiencias de movilidad, supone considerar las condiciones sociales de vida en articulación con los modos singulares de atravesarlas. El abordaje de las movilidades asociadas al turismo resulta una vía posible, y aún poco transitada en los estudios sobre juventudes, para dar cuenta de las singularidades, así como los puntos comunes en las experiencias de los jóvenes latinoamericanos, poniendo en cuestión las imágenes estigmatizantes que recaen sobre éstos, especialmen- 
te en los de sectores populares. Al mismo tiempo, advertir la conformación histórica y social de las juventudes, complejiza y revela nuevas aristas en el abordaje de las prácticas turísticas donde, también, lo metodológico sobre todo desde la propuesta del enfoque biográfico seleccionado - permite advertir los sentidos que los propios jóvenes otorgan a sus prácticas de movilidad.

\section{REFERENCIAS}

Araujo, K. \& Martuccelli, D. (2012). Desafíos comunes. Retratos de la sociedad chilena y sus individuos. Santiago de Chile: LOM.

Bastán, G. \& Paulín, H. (2016). Identidades juveniles en escenarios de periferización urbana. Una aproximación biográfica. Quaderns de Psicologia, 18(1), 35-52.

Bizirgianni, I., \& Dionysopoulou, P. (2013). The influence of tourist trends of youth tourism through social media (SM) \& information and communication technologies (ICTs). Procedia-Social and Behavioral Sciences, 73, 652-660. DOI: https://doi.org/10.1016/i.sbspro.2013.02.102

Cavagnoud, R. (2012). La celebración de los quince años como rito de salida de la infancia para las chicas en el Perú. Umbrales, 22, 95-106.

Chaves, M. \& Segura, R. (eds.) (2015). Hacerse un lugar. Circuitos y trayectorias juveniles en ámbitos urbanos. Buenos Aires: Biblos.

Chaves, M. (2013). Culturas juveniles en la tapa del diario: tensiones entre el margen y el centro de la hoja. En M. Chaves \& E. Fidalgo (comps.), Políticas de infancia y juventud. Producir sujetos y construir Estado. Buenos Aires: Espacio Editorial.

Chaves, M. (2005). Juventud negada y negativizada: representaciones y formaciones discursivas vigentes en la Argentina contemporánea. Última Década, 23, 9-32. DOI: https://doi.org/10.4067/S0718-22362005000200002
Clark, W. A., \& Lisowski, W. (2017). Decisions to move and decisions to stay: Life course events and mobility outcomes. Housing Studies, 32(5), 547565. DOI: https://doi.org/10.1080/02673037.2016.1210100

Coles, T., \& Timothy, D. J. (2004). 'My field is the world': conceptualizing diasporas, travel and tourism: Conceptualizing diasporas, travel and tourism Tourism, migration and mobility: a missing piece of the jigsaw? In T. Coles \& D. J. Timothy (Eds.), Tourism, Diasporas and Space (15-44). London: Routledge.

Cravino, M. C., Duarte, J. \& Del Rio, J. (2008). Magnitud y crecimiento de las villas $y$ asentamientos en el AMBA en los últimos 25 años. Buenos Aires: ULACAV.

Cresswell, T. (2010). Towards a Politics of Mobility. Environment and planning. D, Society and space, 28 (1), 17-31. DOI: https://doi.org/10.1068/d11407

Demeter, T., \& Bratucu, G. (2014). Typologies of youth tourism. Bulletin of the Transilvania University of Brasov. Economic Sciences. Series $V, 7(1), 115$.

Di Leo, P. \& Camarotti, A. (eds.). (2013). 'Quiero escribir mi historia'. Vidas de jóvenes en barrios populares. Buenos Aires: Biblos.

Di Leo, P. \& Camarotti, A. (Dirs.). (2015). Individuación y reconocimiento. Experiencias de jóvenes en la sociedad actual. Buenos Aires: Teseo.

Duarte Quapper, C. (2000). ¿Juventud O Juventudes?: Acerca de cómo mirar y remirar a las juventudes de nuestro continente. Última década, 8(13), 59-77. DOI: https://doi.org/10.4067/S071822362000000200004

Esquivel, J. (2000). Iglesia Católica, política y sociedad: un estudio de las relaciones entre la elite eclesiástica argentina, el Estado y la sociedad en perspectiva histórica. En: Informe final del concurso: Democracia, derechos sociales y equidad; y Estado, política y conflictos sociales. Buenos Aires: CLACSO. 
Farahani, B. M. \& Sukmajati, D. (2011). Youth travelers as a growing market in urban tourism; potencies and challenges. In Conference Environmental Talk: Toward A Better Green Living, Jakarta, Indonesia.

Frändberg, L. (2009). How normal is travelling abroad? Differences in transnational mobility between groups of young Swedes. Environment and Planning A, 41(3), 649-667. DOI: https://doi.org/10.1068/a40234

Glaser, B. \& Strauss, A. (1967). The discovery of grounded theory. Strategies of qualitative research. New York: Aldine.

Glick Schiller, N. \& Salazar, N. (2013). Regimes of mobility across the globe. Journal of ethnic and migration studies, 39(2), 183-200. DOI: https://doi.org/10.1080/1369183X.2013.723253

Gough, K. (2008). 'Moving around': the social and spatial mobility of youth in Lusaka. Geografiska Annaler: Series B, Human Geography, 90(3), 243255. DOI: https://doi.org/10.1111/j.1468$\underline{0467.2008 .290 . x}$

Gough, K. \& Franch, M. (2005). Spaces of the street: socio-spatial mobility and exclusion of youth in Recife. Children's Geographies, 3(2), 149-166. DOI: https://doi.org/10.1080/14733280500161560

Granero Gallegos, A., Ruiz, J., \& García Montes, M. (2005). El Camino de Santiago, una actividad física de recreación y formación para los jóvenes. RETOS. Nuevas Tendencias en Educación Física, Deporte y Recreación, (7), 7-13.

Grellmann, C. \& Pozobon, R. (2010). A comunicação como um elemento de motivação para o comportamento turístico dos jovens. XXXIII Congresso Brasileiro de Ciências da Comunicação Caxias do Sul, RS.

Gutiérrez, A. (2012). ¿Qué es la movilidad? Elementos para (re) construir las definiciones básicas del campo del transporte. Bitácora UrbanoTerritorial, 2(21), 61-74.
Kaufmann, V., Bergman, M., \& Joye, D. (2004).

Motility: Mobility as Capital. International Journal of Urban and Regional Research, 28(4), 745-756. DOI:

https://doi.org/10.1111/i.0309-

$\underline{1317.2004 .00549 . x}$

Laborda, J. (2007). Language travel or language tourism: have educational trips changed so much? Online Submission.

Leclerc-Olive, M. (2009). Temporalidades de la experiencia: las biografías y sus acontecimientos. Iberofórum. Revista de Ciencias Sociales de la Universidad Iberoamericana, 4(8), 1-39.

Lyons, K., Hanley, J., Wearing, S., \& Neil, J. (2012). Gap year volunteer tourism: Myths of global citizenship? Annals of tourism research, 39(1), 361378. DOI:

https://doi.org/10.1016/i.annals.2011.04.016

Martuccelli, D. (2007). Cambio de rumbo. La sociedad a escala del individuo. Santiago de Chile: LOM.

Martín-Cabello, A. (2014). El turismo «backpacker» en Chile como expresión de una subcultura juvenil global. Cuadernos de Turismo, (34), 165-188.

Morgan, M. \& Xu, F. (2009). Student travel experiences: Memories and dreams. Journal of Hospitality Marketing \& Management, 18(2-3), 216-236.

DOI:

https://doi.org/10.1080/19368620802591967

Noy, C. (2004). This trip really changed me: Backpackers' narratives of self-change. Annals of Tourism research, 31(1), 78-102. DOI: https://doi.org/10.1016/i.annals.2003.08.004

Quinn, B. \& Stacey, J. (2010). The benefits of holidaying for children experiencing social exclusion: Recent Irish evidence. Leisure Studies, 29(1), 29-52. DOI: https://doi.org/10.1080/02614360903046631

Richards, G. (2015). The new global nomads: Youth travel in a globalizing world. Tourism Recreation Research, 40(3), 340-352. DOI: https://doi.org/10.1080/02508281.2015.1075724 
Reguillo, R. (2012). Culturas Juveniles: Formas políticas del desencanto. Buenos Aires: Siglo Veintiuno.

Saraví, G. (2014). Youth experience of urban inequality: space, class, and gender in Mexico. In: Wyn, J. \& H. Cahill (Eds.). Handbook of childhood and youth. Singapore: Springer, 1-11. DOI: https://doi.org/10.1007/978-981-4451-96-3 45-1

Schenkel, E. (2013). El derecho de las personas al turismo en Argentina. Una aproximación desde la justicia social. Revista Líder, 22(15), 189-206.

Schrooten, M., Salazar, N., \& Dias, G. (2016). Living in mobility: trajectories of Brazilians in Belgium and the UK. Journal of Ethnic and Migration Studies, 42(7), 1199-1215. DOI: https://doi.org/10.1080/1369183X.2015.1089160

Scribano, A. (2008). El proceso de investigación social cualitativo. Buenos Aires: Editorial Prometeo Libros.

Sheller, M. (2014). Sociology after the mobilities turn. The Routledge Handbook of Mobilities. London and New York: Routledge, 45-54.

Sheller, M., \& Urry, J. (eds) (2004). Tourism Mobilities: Places to play, places in play. Routledge: Londres. DOI: https://doi.org/10.4324/9780203340332

Sheller, M., \& Urry, J. (2006). The new mobilities paradigm. Environment and Planning, 38, 207-226. DOI: https://doi.org/10.1068/a37268
Soneira, A. (2012). La 'Teoría fundamentada en los datos' (Grounded Theory) de Glaser y Strauss. En I. Vasilachis de Gialdino (coord.), Estrategias de investigación cualitativa. Barcelona: Ed. Gedisa, 153-174.

Souza Minayo, M. C. (org.) (2007). Investigación social: teoría, método y creatividad. Buenos Aires: Lugar Editorial.

Vasilachis De Gialdino, I. (2009). Ontological and Epistemological Foundations of Qualitative Research. Forum Qualitative Sozialforschung / Forum: Qualitative Social Research, 10(2).

Vasilachis De Gialdino, I. (coord.) (2012). Estrategias de investigación cualitativa. Barcelona: Ed. Gedisa.

Informaciones sobre el autor:

\section{Silvia Alejandra Tapia}

Doctora de la Universidad de Buenos Aires (UBA) en Ciencias Sociales. Magíster de la UBA en Políticas Sociales. Investigadora Asistente del Consejo Nacional de Investigaciones Científicas y Técnicas (CONICET), con sede en el Instituto de Investigaciones Gino Germani (IIGG), Facultad de Ciencias Sociales, UBA.

E-mail: tapiasilvi1@gmail.com

ORCID: https://orcid.org/0000-0003-0106-7023 